\title{
The mitochondrial genome of Paragonimus westermani (Kerbert, 1878), the Indian isolate of the lung fluke representative of the family Paragonimidae (Trematoda)
}

Among helminth parasites, Paragonimus (zoonotic lung fluke) gains considerable importance from veterinary and medical point of view because of its diversified effect on its host. Nearly fifty species of Paragonimus have been described throughout the globe. It is estimated that more than 20 million people are infected worldwide and the best known species is Paragonimus westermani, whose type locality is probably India and which infects millions of people in Asia causing disease symptoms that mimic tuberculosis. Human infections occur through eating raw crustaceans containing metacercarie or ingestion of uncooked meat of paratenic hosts such as pigs. Though the fluke is known to parasitize a wide range of mammalian hosts representing as many as eleven families, the status of its prevalence, host range, pathogenic manifestations and its possible survivors in nature from where the human beings contract the infection is not well documented in India. We took advantage of the whole genome sequence data for $P$. westermani, generated by Next Generation Sequencing, and its comparison with the existing data for the $P$. westermani for comparative mt DNA phylogenomic analyses. Specific prmers were designed for the 12 protein coding genes with the aid of existing $P$. westermani mtDNA as the reference. The lon torrent next generation sequencing platform was harnessed to completely sequence the mitochondrial genome, and applied innovative approaches to bioinformatically assemble and annotate it. A strategic PCR primer design utilizing the whole genome sequence data from $P$. westermani enabled us to design specific primers capable of amplifying all regions of the mitochondrial genome from $P$. westermani. Assembly of NGS data from libraries enriched in mtDNA sequence by PCR gave rise to a total of 11 contigs spanning the entire $14.7 \mathrm{~kb}$ mt DNA sequence of $P$. westermani available at NCBI. We conducted gap-filling by traditional Sanger sequencing to fill in the gaps. Annotation of non-protein coding genes successfully identified tRNA regions for the 24 tRNAs coded in mtDNA and 12 protein coding genes. Bayesian phylogenetic analyses of the 
concatenaed protein coding genes placed $P$. westermani within the family Opisthorchida. The complete mtDNA sequence of $P$. westermani is 15004 base pair long; the lung fluke is the major etiological agent of paragonimiasis and the first Indian represenative for the family Paragonimidae to be fully sequenced that provides important genetic markers for ecological, population and biogeographical studies and molecular diagnostic of digeneans that cause trematodiases. 
2 Devendra K Biswal ${ }^{1}$, Anupam Chatterjee ${ }^{2}$, Alok Bhattacharya ${ }^{3, *}$, Veena Tandon ${ }^{1,4, *}$ 3

$4 \quad{ }^{1}$ Bioinformatics Centre, North-Eastern Hill University, Shillong 793022, Meghalaya, India

$5{ }^{2}$ Department of Biotechnology and Bioinformatics, North-Eastern Hill University, Shillong

6 793022, Meghalaya, India

$7 \quad{ }^{3}$ School of Life Sciences, Jawaharlal Nehru University, New Delhi 110067, India

$8{ }^{4}$ Department of Zoology, North-Eastern Hill University, Shillong 793022, Meghalaya, India

$9{ }^{*}$ Corresponding author

10

11 Email addresses:

12 DKB: devbioinfo@gmail.com

13 AC: chatterjeeanupam@hotmail.com

14 AB: alok.bhattacharya@gmail.com

$15 \quad$ VT: tandonveena@gmail.com

16

17

18

19

20 


\section{Introduction}

22 Among about 50 known species of the genus Paragonimus, Paragonimus westermani, one of the

23 causative agents of paragonimiasis, was first described as early as in 1878 and is the most well-

24 known species within the genus Paragonimus because of its wide geographical distribution and

25 medical importance (Blair, XU \& Agatsuma, 1999). Typically, paragonimiasis is a disease of the

26 lungs and pleural cavity but extra-pulmonary paragonimiasis also happens to be an important

27 clinical manifestation. It is a neglected disease that has received feeble attention from public

28 health authorities. As per the recent estimates, about 293 million people are at risk, while several

29 millions are infected worldwide (Keiser \& Utzinger, 2009). However, this may be an

30 underestimate as there are still many places where the disease burden has yet to be assessed.

31 There has been an increased recognition of the public health importance of paragonimiasis and

32 other foodborne trematodiases in recent times (Fried, Graczyk \& Tamang, 2004) and some

33 serious concern for Paragonimus species outside endemic areas owing to the risk of infection

34 through food habits in today's globalized food supply. In the case of paragonimiasis, this

35 resurgence of interest can partly be attributed to the common diagnostic confusion of

36 paragonimiasis with tuberculosis, as symptoms of the former closely mimic those of the latter,

37 thereby leading to an inappropriate treatment being administered especially in areas where both

38 tuberculosis and paragonimiasis co-occur and create overlapping health issues (Toscano et al.,

39 1995). The state-of-the-art molecular biology techniques, next generation sequencing (NGS)

40 technology and their rapid development in contemporary times may provide additional tools for

41 the differential identification of digenean trematode infections to overcome limitations of current

42 morphology-based diagnostic methods. Owing to their high nucleotide substitution rates,

43 parasitic flatworm mitochondrial (mt) genomes have become very popular markers for diagnostic

44 purposes and for resolving their phylogenetic relationships at different taxonomic ranks. 
45 Comparative mitochondrial genomics can provide more reliable results and reveal important

46 informations of mtDNA architectural features such as gene order and structure of non-coding

47 regions.

48 At present there have been reports on two isolates of $P$. westermani mtDNA, one diploid (2n)

49 mtDNA (incomplete) from Leyte Island, Philippines that resembles $P$. westermani

50 morphologically and is sometimes regarded as a subspecies, P. westermani filipinus (Sato et al.,

51 2002) and one triploid (3n) complete Korean P. westermani isolate mtDNA (accession:

52 NC_002354 complete, unpublished). In our present study, we determined the complete mtDNA

53 nucleotide sequence of $P$. westermani, which was collected from several sites in Changlang

54 District, Arunachal Pradesh in India, using NGS data generated from total genomic DNA

55 extracts. Phylogenetic analyses were carried out using a supermatrix of all the concatenated $\mathrm{mt}$

56 sequences of 12 protein-coding genes of digenean trematode and cestodes, (taking nematode

57 species as an outgroup) available in public domain (GenBank ). This newly sequenced Indian

58 isolate $P$. westermani $\mathrm{mt}$ genome sequence along with the one in the RefseQ database bearing

59 accession NC_002354 of NCBI would provide useful information on both genomics and

60 Paragonimidae evolution, including the biogeographic status of the cryptic species of the lung

61 flukes and other mtDNA sequences available for any member of the trematode group.

\section{Methods}

63 Parasite material and DNA extraction

64 Naturally infected freshwater edible crabs (Barytelphusa lugubris lugubris) were collected from

65 Changlang District in Arunachal Pradesh (altitude - $213 \mathrm{mASL}$, longitude - $96^{\circ}-15^{\prime} \mathrm{N}$ and latitude

$\left.66-27^{\circ}-30^{\prime} \mathrm{E}\right)$. The isolation of metacercariae from the crustacean host muscle tissues was carried

67 out by digestion technique using artificial gastric juice. The $70 \%$ alcohol-fixed metacercariae

68 were further processed for DNA extraction and PCR amplification. The lysed individual worms 
69 were subjected to DNA extraction by standard ethanol precipitation technique (Sambrook, Fitsch

70 \& Maniatis, 1989); DNA was also extracted from individual metacercarie on FTA cards with the

71 aid of Whatman's FTA Purification Reagent.

72 Primer design strategy and PCR

73 Illumina reads from our unpublished $P$. westermani whole genome data were mapped to 74 P.westermani reference sequence (gi|23957831|ref|NC_002354.2|). The alignment was carried out

75 using Bowtie aligner. The mapped reads were extracted in fastq format using custom perl script.

76 We obtained 62874 paired end reads, which aligned to different intervals in the P.westermani mt

77 genome, covering $\sim 3 \mathrm{~kb}$ of the $15 \mathrm{~kb} \mathrm{mt}$ genome (NC_002354.2). Accordingly, primers were

78 designed at these regions, using sequence information from reference to ensure optimum primer

79 design (Additional file 1). We conducted PCR using $10 \mathrm{ng}$ of genomic DNA from P. westermani

80 with the following PCR conditions: $10 \mathrm{ng}$ of FD-2 DNA with $10 \mathrm{uM}$ Primer mix in $10 \mathrm{ul}$

81 reaction, PCR thermo cycling conditions $-98^{\circ} \mathrm{C}$ for $3 \mathrm{~min}, 35$ cycles of $98{ }^{\circ} \mathrm{C}$ for $30 \mathrm{sec}, 60^{\circ} \mathrm{C}$

82 for $30 \mathrm{sec}, 72{ }^{\circ} \mathrm{C}$ for $1 \mathrm{~min} 30 \mathrm{sec}$, final extension $72^{\circ} \mathrm{C}$ for $3 \mathrm{~min}$ and $4^{\circ} \mathrm{C}$ hold. We gel-eluted the

83 bands (Additional file 1) corresponding to different products, pooled these products and

84 proceeded for NGS library construction. These clean single end reads were also further used for

85 bioinformatics analysis in this study. The Illumina mito mapped reads were quality checked using

86 Genotypic Technology Pvt. Ltd., proprietary tool SeqQC. The QC reads are outlined in Table 5.

88 NGS Library construction, sequencing and assembly:

89 DNA was subjected to a series of enzymatic reactions that repair frayed ends, phosphorylate the

90 fragments, and add a single nucleotide 'A' overhang and ligate adaptors (Illumina's TruSeq DNA

91 sample preparation kit). Sample cleanup was done using Ampure XP SPRI beads. After ligation,

$92 \sim 300-350 \mathrm{bp}$ fragment for short insert libraries and $\sim 500-550 \mathrm{bp}$ fragment for long insert

93 libraries were size-selected by gel electrophoresis, gel extracted and purified using Minelute 
94 columns (Qiagen). The libraries were amplified using 10 cycles of PCR for enrichment of

95 adapter-ligated fragments. The prepared libraries were quantified using Nanodrop and validated 96 for quality by running an aliquot on High Sensitivity Bioanalyzer Chip (Agilent). 2X

97 KapaHiFiHotstart PCR ready mix (Kapa Biosystems Inc., Woburn, MA) reagent was used for

98 PCR. The Ion Torrent library was made using Ion Plus Fragment library preparation kit (Life

99 Technologies, Carlsbad, US) and the Illumina library was constructed using TruSeqTM DNA

100 Sample Preparation Kit (Illumina, Inc., US) reagents for library prep and TruSeq PE Cluster kit

101 v2 along withTruSeq SBS kit v5 36 cycle sequencing kit (Illumina, Inc., US) for sequencing

102 (Biswal et al., 2013). PCR products were sonicated, adapter ligated and amplified for $\mathrm{x}$ cycles to

103 generate a library and subsequently were sequenced to generate reads of an average of $121 \mathrm{nt} \mathrm{SE}$

104 reads on Ion Torrent. The IonTorrent raw data was processed for 3' low quality bases trimming,

105 and adapter contamination. Since the Ion Torrent data might have had host contamination, the

106 processed reads were then aligned to the reference sequence of Paragonimus westermani mtDNA

107 (NC_002354) available in GenBank, Department of Environmental Health Science, Kochi

108 Medical School, Oko, Nankoku, Kochi, Japan. The alignment was carried out using Tmap Ion

109 Torrent proprietary tool. The mapped reads were extracted in fastq format using custom perl

110 script. These clean reads were used for further bioinformatics analysis in this study. The

111 processed reads as well as mito-mapped reads were quality checked using Genotypic Technology

112 Pvt. Ltd., proprietary tool SeqQC.

113 De-novo Assembly

114 The Ion Torrent-mapped reads were assembled using Newbler (Quinn et al., 2008) software. The

115 Illumina-mapped reads were subjected to reference assisted de novo assembly using velvet

116 (Zerbino \& Birney, 2008) assembler. Quite a few hash lengths were tested for velvetg. Hash

117 length 65 gave the optimal results in terms of total contig length, N50, and maximum contig

118 length. Therefore, k-mer 65 assembly was considered for further analysis. Sanger reads were also 
119 added in the final assembly. The draft sequence was generated using Ion Torrent reads, Illumina

120 reads, Sanger reads, hybrid high-quality de novo assembly and subsequently the de novo-leftout

121 regions were obtained using reference assisted assembly and consensus calling. Extensive manual

122 curation work was carried out to produce the complete sequence. The complete sequence

123 comprises 15,004 bases in total. There were a few regions in the mitochondrial sequence, namely

$124 \sim 900$ bases in the start and $\sim 1500$ bases in the end, where there were few or no sequences at $3 x$

125 depth. In that case, the consensus sequence was retrieved using VCFtools (Danecek et al., 2008).

126 The consensus sequence was introduced at such regions; the sequences in question are

127 represented by letters in lower case of nucleotides, while the confident regions are represented in

128 upper case in the fasta sequence file.

129 In silico analysis for nucleotide sequence statistics, protein coding genes (PCGs) 130 prediction, annotation and tRNA prediction

131 Sequences were assembled and edited by using CLC Genome Workbench V.6.02 with

132 comparison to published flatworm genomes and the assembled whole single mtDNA contig was

133 annotated with the aid of ORF finder tool at NCBI (http://www.ncbi.nlm.nih.gov/gorf/gorf.html)

134 and MITOS, which were subsequently used to search for homologous digenean trematode PCGs

135 already housed in REFSEQ NCBI database (http://www.ncbi.nlm.nih.gov/refseq/ ) by using

136 tBLASTn [Altschul et al., 1990). The program ARWEN (Laslett \& Canbäck, 2008) was used to

137 identify the tRNA genes by setting the search to predict secondary structures occasionally with

138 very low Cove scores $(<0.5)$ and, where necessary, also by restricting searches to find tRNAs

139 lacking DHU arms (using the trematode tRNA option). Nucleotide codon usage for each protein-

140 encoding gene was predicted using the program Codon Usage at

141 (http://www.bioinformatics.org/sms2/codon_usage.html). The ORFs and codon usage profiles of

142 PCGs were analyzed. The newly sequenced and assembled P. westermani mtDNA was annotated 
143 using MITOS and the output file was further used to sketch the newly sequenced genome with

144 GenomeVX at http://wolfe.ucd.ie/GenomeVx/

146 Phylogenetic analysis

147 DNA sequences of the 12 protein-coding genes from 13 representative trematode, cestode and

148 nematode species were retrieved (Table 1), aligned in clustal w and concatenated using

149 MESQUITE (Maddison \& Maddison, 2011). The supermatrix was used for generating

150 phylogenetic trees using Bayesian analysis in MrBayes v3.1 (Ronquist and Huelsenbeck, 2003).

151 The mt genome sequences of the nematode Ascaris suum and Ascaris lumbricoides were used as

152 an outgroup. For the nucleotide alignment, the $\mathrm{GTR}+\mathrm{I}+\mathrm{G}$ model was used and Bayesian analysis

153 was run for $1,000,000$ generations and sampled every 1,000 generations. The first $25 \%$ of trees

154 were omitted as burn-in and the remaining trees were used to calculate Bayesian posterior

155 probabilities retaining the trees with a majority consensus rule of 50.

\section{Results \& Discussion}

\section{Mitochondrial genome organisation of $\boldsymbol{P}$. westermani mtDNA}

158 The two rRNA genes and 12 protein coding genes, typical of the flatworms, were identfied by

159 comparison of their sequence similarity and secondary structures with those of other flatworms.

160 The $\mathrm{mt}$ genome lacks ATP synthase protein 8 (ATP8) with no characteristic amino acid

161 signatures. Over a long time gene order remains stable in animal mtDNAs [Boore, 1999; Saccone

162 et al., 1999). Differences in the mtDNA gene order between members of the same family, though

163 rare, can occur in higher taxonomic ranks. A marked difference in the gene order was found

164 among the various trematode, cestode and nematode species as outlined in Fig. 1. The total length

165 for the digenean P. westermani (AF219379) is 14,965 bp, and for Schistosoma japonicum

166 (NC_002544) and S. mansoni (NC_002545) is approximately $14.5 \mathrm{~kb}$ as curated by the NCBI

167 staff. Other digeneans possess small $\mathrm{mt}$ genomes. The mtDNA sequence of $P$. westermani 
168 (Bioproject accession number PRJNA248332, Biosample accession sample SAMN02797822

169 and SRA SRX550161) is 15,004 bp in length and is well within the range of typical metazoan

170 mtDNA sizes $(14-18 \mathrm{~kb})$. The $\mathrm{mt}$ genome of $P$. westermani is larger than that of other digenean

171 species available in GenBank (http://www.ncbi.nlm.nih.gov/genbank/) to date (Table 1). It

172 contains 12 protein-coding genes (cox1-3, nad1-6, nad4L, atp6 and cytb), 24 transfer RNA

173 (tRNA) genes and 2 ribosomal RNA genes (rrnL and rrnS) (Fig. 2, Table 2). The gene

174 arrangement pact of protein-coding genes in $P$. westermani tallies with that of Fasciola hepatica

175 (Le et al., 2000; Le et al., 2001), Opisthorchis felineus (Shekhovtsov et al., 2010), Fasciola

176 gigantica (Liu et al., 2014), Fasciolopsis buski (Biswal et al., 2013) and Paramphistomum cervi

177 [Yan et al., 2013) $\mathrm{mt}$ genomes, but is different from that seen in Taenia and Ascaris species

178 (Nakao, Sako \& Ito, 2003; Okimoto, Macfarlane \& Wolstenholme, 1990) (Fig. 3). An

179 overlapping region spanning nearly 40 bp between 3' nad4L end and nad4 5' end was also seen in

180 P.westermani, a feature common to other digenean trematodes. The 12 protein coding genes and

181 their blast hit protein plots are summarised in Fig. 4. The protein plot shows for each gene and

182 each position the quality value if it is above the threshold; the different genes are differentiated

183 with a range of colour codes. Basically, the initial hits used in MITOS [Bernt et al., 2013)

184 correspond to the "mountains" in this plot that visualizes the signal from the BLAST searches

185 (Altschul et al., 1990). The arrows shown on the top of the plot depict the gene order annotation

186 and the quality values are shown on a log scale.

188 Comparison of mtDNA between $P$. westermani of Indian and Korean isolates

189 The complete $P$. westermani Indian isolate mtDNA comprises of 15,004 bases in total while the

190 Korean isolate (NC_002354) is of 14,965 bp in length. Out of 15,004 bases in the sequences,

19113,188 bases were confident bases (87.88\% of total), while 1818 bases were low quality bases

192 (12.11\% of total). Mapping of assembled mitochondria against the reference Korean isolate was 
193 carried out using online Blastn that show 85\% identical bases between the two, with $99 \%$ query

194 coverage with the best possible e-value of 0.0 and with a maximum score of 12579 . A dot plot 195 matrix view was generated depicting the sequence similarity regions on the reference sequence.

196 The $\mathrm{x}$-axis represents the assembled sequence, whereas y-axis represents the reference sequence

197 (Fig. 5A). In order to generate visual output of the mapped assembled mtDNA against the

198 reference mtDNA, standalone blast and Artemis Comparison Tool (ACT) was incorporated

199 (Carver et al., 2005). Sequence similarity map (Fig. 5B) shows dark red links where high \%

200 identical synteny is found between reference and query sequence. No complete NR is known for

201 P. westermani in both the Indian and Korean mtDNA. The melting temperatures, count and

202 frequency of atoms in both single stranded and double stranded DNA, count and frequency of

203 nucleotides showed little variation and are outlined in Table 4. The percentage nucleotide

204 variation for $\mathrm{A}$ and $\mathrm{T}$ was higher in Indian isolate compared to the Korean mtDNA while the G,C

205 percentage was higher in the Korean isolate (Fig. 6). In both the mtDNAs there are 12 protein

206 coding genes and 1 rRNA with a variation in the number of tRNAs i.e., 24 in the Indian isolate as

207 compared to the Korean mtDNA with 23 tRNAs.

\section{Genetic Code, nucleotide composition and codon usage}

209 It is a well established fact that mtDNA of parasitic flatworms uses AAA to specify ASN (Lys in

210 the universal code), AGA and AGG to specify Ser (Arg in the universal code), and TGA to

211 specify Trp (stop codon in the universal code). ATG is the usual start codon while GTG and other

212 codons are also used as start codons ( Le et al., 2002). The P. westermani mtDNA exhibited ATG

213 and ATA as start codons and TAG and TAA as stop codons (Table 3). mtDNA genomes of

214 invertebrates have a tendency to be AT-rich (Wolstenholme, 1992), a feature common in several

215 parasitic flatworm protein coding genes. However, the nucleotide composition is not uniform

216 among the species. For Schistosoma mansoni, the AT-rich percentage is $68.7 \%$, whereas for

217 Fasciola hepatica it is $63.5 \%$ AT and for P. westermani only 54.6\% AT (Le et al., 2002). The 
218 nucleotide composition in the $P$. westermani Indian isolate was biased towards $\mathrm{G}$ and $\mathrm{T}$, which is

219 similar to that of other digeneans, viz. F. hepatica, O. felineus, C. sinensis, $P$. cervi; unlike $S$.

220 japonicum and other schistosomes, which are more biased towards $\mathrm{A}$ and $\mathrm{T}$. The atomic

221 composition in single stranded DNA exhibits hydrogen with a frequency of $37.5 \%$, carbon

$22229.8 \%$, nitrogen $10.8 \%$, oxygen $18.8 \%$ and phosphorus $3.0 \%$ (Table 4 ).

\section{Transfer and ribosomal RNA genes section}

224 A standard cloverleaf structure is generally seen for most of the tRNAs. There are exceptions that

225 include tRNA(S), in which the paired dihydrouridine (DHU) arm is missing as in all parasitic

226 flatworm species and tRNA(A), in which the paired DHU-arm is missing as in cestodes contrary

227 to trematodes. Previous studies indicate structures for tRNA(C) that somewhat vary among the

228 parasitic flatworms. In some species, a paired DHU-arm is missing (Schistosoma mekongi and

229 cestodes), whereas it is present in others (F.hepatica and F. buski). It is noteworthy that the $P$.

230 westermani Indian isolate exhibited 24 tRNA genes, 1 TV replacement loop tRNA genes and 2 D

231 replacement loop tRNA genes. The tRNA GC range varied from 37.9\% to 59.4\%. (Fig. 7).

232 Ribosomal large and small subunits in parasitic flatworms are unremarkable. They are smaller

233 than those in most other metazoans but can be folded into a recognizable, conserved secondary

234 structures (Le et al., 2001). The rrnL (16S ribosomal RNA) and rrnS (12S ribosomal RNA) genes

235 of $P$. westermani were identified by sequence comparison with those of cloesly related

236 trematodes and these ribosomal genes were separated by tRNA-C (GCA).

\section{Non-coding regions}

238 There are one or two longer non-coding region(s) (NR) in every genome comprising stable stem-

239 loop structures that are associated with genome replication or repeat sequences. Previous studies

240 report repeats in the NR of many animal $\mathrm{mt}$ genomes that may be an outcome of slippage-

241 mismatching mechanisms (Le, Blair \& McManus, 2001). In parasitic flatworms, NRs vary in

242 length and complexity. The NR is divided by one or more tRNA genes into a SNR and a LNR in 
243 digenean trematodes. A common feature of LNRs is the presence of long repeats. In the present

244 study the $P$. westermani mtDNA though didn't exhibit significant demarcation of LNR and SNR,

245 there were regions with repeats with total number of 3158 variants with a total of 1722 SNPs and

2461436 INDELS.

\section{Phylogenetic analysis}

248 Several genetic markers from nuclear rDNA regions and mtDNA of flukes have been employed

249 in some systematic and population genetic studies of helminth parasites [7-14]. As of now the 250 full-length $\mathrm{mt}$ genomes of 14 digenean, 34 cestode and 70 nematode species have been 251 determined, characterized, and are published in GenBank. It is confirmed that alignments with 252 more than 10,000 nucleotides from mtDNAs can provide ample information for phylogenetic 253 resolution, hypothesis building and evolutionary interpretation of the major lineages of 254 tapeworms. Use of complete mtDNA sequences for phylogenetic analyses are more reliable and 255 informative (Waeschenbach, Webster \& Littlewood, 2012). In the present study, a phylogenetic 256 tree inferred from concatenated nucleotide sequences of the 12 protein-coding genes (shown in 257 Fig. 2) is well supported by very high posterior probabilities (100\%). Two large clades are visibly 258 informative: one contains members of the Family Schistosomatidae, and the other includes 259 members representing the sequence of families in order of increasingly derived status: 260 Opisthorchiidae, Paragonimidae, Paramphistomidae and Fasciolidae (Trematoda); Ascarididae 261 (Nematoda) and Taeniidae (Cestoda). This arrangement was seen in the tree based on nucleotide 262 sequences, in which a clade containing Fasciolidae and Paragonimidae members was strongly 263 supported and P. cervi was sister to this clade. P. westermani claded with Opisthorchis felineus 264 and Clonorchis sinensis. Members representing Taeniidae served as an outgroup (Fig. 3). 


\section{Conclusions}

266 In this study, we took advantage of the whole genome sequence data generated by NGS 267 technology for $P$. westermani Indian isolate and its comparison to existing data for the $P$.

268 westermani (Korean isolate) mitochondrial genome for the purpose of comparative analysis

269 between the $\mathrm{mt}$ genomes of the two isolates. Precise and specific primers were designed for

270 amplification of mitochondrial genome sequences from the parasite DNA sample with the help of

271 existing $P$. westermani mtDNA available in the NCBI Refseq database. Here we present and 272 discuss the complete sequence of the coding region of the mitochondrial genome of $P$.

273 westermani, the Indian lung fluke isolate, which posesses the same gene order as that of other 274 Digenea (Opisthorchidae and Paramphistomatidae) and consists of 12 PCGs, 24 tRNAs and 2 275 rRNAs. There are long repetitive regions in the fluke that can serve as diagnostic markers with

276 phylogenetic signals. The complete mtDNA sequence of $P$. westermani will add to the knowledge 277 of digenean mitochondrial genomics and also provide an important resource for studies of inter278 and intra-specific variations, biogeographic studies, heteroplasmy of the flukes belonging to 279 Paragonimidae and a resource for comparative mitochondrial genomics and systematic studies of 280 Digenea in general.

281 Availability of supporting data

282 Sequence reads have been deposited at the National Center for Biotechnology Information 283 [Bioproject: PRJNA248332, Biosample : SAMN02797822 and SRA: SRX550161] 
284

285

286

287

288

289

290

291

292

293

294

295

296

297

298

299

300

301

302

303

304

305

306

\section{Authors' contributions}

$\mathrm{VT}, \mathrm{AB}$ and $\mathrm{DKB}$ conceived of the study and participated in its design, coordination and manuscript writing. $\mathrm{DKB}$ and $\mathrm{AB}$ performed the computational analysis and maintained the computer programs used for the analysis. VT and AC performed the molecular experiments associated with the parasite. All authors have read and approved the final manuscript.

\section{Acknowledgements}

We would like to acknowledge Dr. Sudip Ghatani, Department of Zoology, NEHU, Shillong for collecting the biosamples and M/s Genotypic Technologies, Bangalore, India for carrying out NGS sequencing for this project, especially the efforts of Dr. Deepti Saini for the primer design strategy.

\section{References}

1. 1 Altschul SF, Gish W, Miller W, Myers,E.W. \& Lipman DJ. 1990. Basic local alignment search tool. Journal of Molecular Biology 215:403-410

2. Biswal DK, Ghatani S, Shylla JA, Sahu R, Mullapudi N, Bhattacharya A, TandonV. 2013. An integrated pipeline for next generation sequencing and annotation of the complete mitochondrial genome of the giant intestinal fluke, Fasciolopsis buski (Lankester, 1857) Looss, 1899. PeerJ 1:e207

3. Bernt M, Donath A, Jühling F, Externbrink F, Florentz C, Fritzsch G, Pütz J, Middendorf M, Stadler PF. 2013. MITOS: Improved de novo Metazoan Mitochondrial Genome Annotation. Molecular Phylogenetics and Evolution 69:313-319

4. Blair D, Xu ZB, Agatsuma T. 1999. Paragonimiasis and genus Paragonimus. Advance Parasitology 42:113-222 
5. Boore J.L. 1999. Animal mitochondrial genomes. Nucleic Acids Research 27 :17671780

6. Carver TJ, Rutherford KM, Berriman M, Rajandream MA, Barrell BG, Parkhill J. 2005. ACT: the Artemis Comparison Tool. Bioinformatics 16:3422-3.

7. Danecek P, Auton A, Abecasis G, Albers CA, Banks E, DePristo MA, Handsaker RE,Lunter G, Marth GT, Sherry ST, McVean G, Durbin R; 1000 Genomes Project Analysis Group. 2011. The variant call format and VCFtools. Bioinformatics 27:21568.

8. Fried B, Graczyk TK, Tamang L. 2004. Food-borne intestinal trematodiases in humans. Parasitology Research 93:159

10. Laslett D, Canbäck B. 2008. ARWEN: a program to detect tRNA genes in metazoanmitochondrial nucleotide sequences. Bioinformatics 2:172-5.

321 11. Le TH, Blair D, Agatsuma T, Humair PF, Campbell NJ, et al. 2000. Phylogenies inferred 322 from mitochondrial gene orders- a cautionary tale from the parasitic flatworms. $323 \quad$ Molecular Biology and Evolution 17: 1123-1125.

324 12. Le TH, Blair D, McManus DP. 2001. Complete DNA sequence and gene organization 325 of the mitochondrial genome of the liverfluke, Fasciola hepatica L. (Platyhelminthes; Trematoda). Parasitology 123:609-21.

327 13. Le TH, Blair D, McManus DP. 2001. Complete DNA sequence and gene organization 328 of the mitochondrial genome of the liverfluke, Fasciola hepatica L. (Platyhelminthes; 329 Trematoda). Parasitology 123: 609-621.

330 14. Le TH, Blair D, McManus DP. 2002. Mitochondrial genomes of parasitic 331 flatworms.Trends in Parasitology 18:206-13 
332 15. Liu GH, Gasser RB, Young ND, Song HQ, Ai L, Zhu XQ. 2014. Complete 333 mitochondrial genomes of the 'intermediate form' of Fasciola and Fasciola gigantica, 334 and their comparison with $\boldsymbol{F}$. hepatica. Parasites and Vectors. 2014, 7:150.

335 16. Maddison, WP, Maddison DR. 2011. Mesquite: a modular system for incoevolutionary 336 analysis. Version 2.75 Available at http://mesquiteproject.org

337 17. Nakao M, Sako Y, Ito A. 2003. The mitochondrial genome of the tapeworm Taenia 338 solium: a finding of the abbreviated stop codon U. Journal of Parasitology 89:633-5.

339 18. Okimoto R, Macfarlane JL, Wolstenholme DR. 1990. Evidence for the frequent use of 340 TTG as the translation initiation codon of mitochondrial protein genes in the nematodes, Ascaris suum and Caenorhabditis elegans. Nucleic Acids Research 18:6113-8.

19. Quinn NL, Levenkova N, Chow W, Bouffard P, Boroevich KA, Knight JR, Jarvie TP, Lubieniecki KP, Desany BA, Koop BF, Harkins TT, Davidson WS. 2008. Assessing the feasibility of GS FLX Pyrosequencing for sequencing the Atlantic salmon genome. BMC Genomics 9:404

20. Ronquist F, Huelsenbeck JP. 2003. MRBAYES 3: Bayesian phylogenetic inference under mixed models. Bioinformatics 19:1572-1574

349 21. Saccone C, De Giorgi C, Gissi C, Pesole G, Reyes A. 1999. Evolutionary genomics in 350 Metazoa: the mitochondrial DNA as a model system. Gene 238:195-209

351 22. Shekhovtsov SV, Katokhin AV, Kolchanov NA, Mordvinov VA. 2010. The complete 352 mitochondrial genomes of the liver flukes Opisthorchis felineus and Clonorchis 353 sinensis (Trematoda). Parasitology International 59: 100-103

354 23. Toscano C, Sen Hai Yu, Nunn P, Mott KE. 1995. Paragonimiasis and tuberculosis, 355 diagnostic confusion: a review of the literature. Tropical Diseases Bulletin 92: R1 
356 24. Wolstenholme DR. 1992. Animal mitochondrial DNA, structure and evolution.

357 International Review of Cytology 141: 173-216

358 25. Waeschenbach A, Webster BL, Littlewood DT. 2012. Adding resolution to ordinal level 359 relationships of tapeworms (Platyhelminthes: Cestoda) with large fragments of 360 mtDNA. Molecular Phylogenetics and Evolution. 63: 834-847

361 26. Yan HB, Wang XY, Lou ZZ, Li L, Blair D, Yin H, Cai JZ, Dai XL, Lei MT, Zhu XQ, Cai 362 XP, Jia WZ. 2013. The mitochondrial genome of Paramphistomum cervi (Digenea), 363 the first representative for the family Paramphistomidae. PLoS One. 8:e71300

364 27. Zerbino DR, Birney E. 2008. Velvet: algorithms for de novo short read assembly using 365 de Bruijn graphs. Genome Research 18:821-9. 


\section{Figure 1}

Comparative Synteny map of the representative species for the helminth mtDNA illustrating the protein coding genes, tRNAs, rRNAs etc. 
Schistosoma japonicum NC_002544

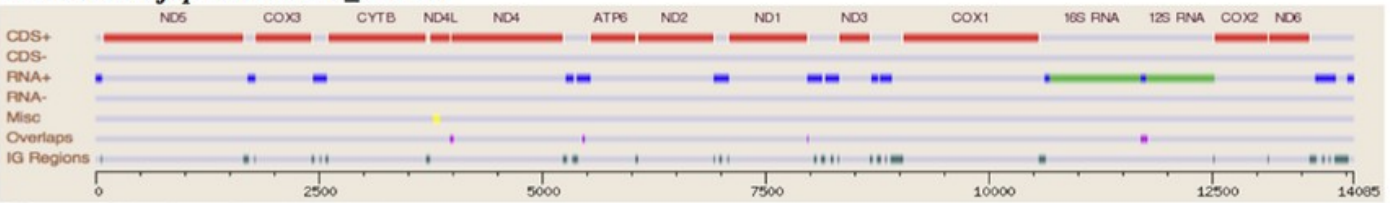

\section{Clonorchis sinensis NC_012147}

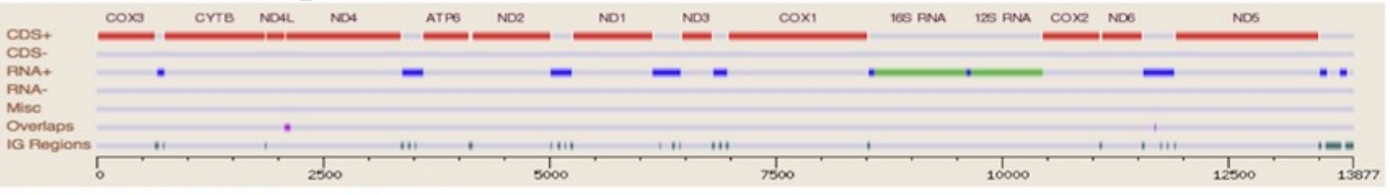

Opisthorchis felineus NC_011127

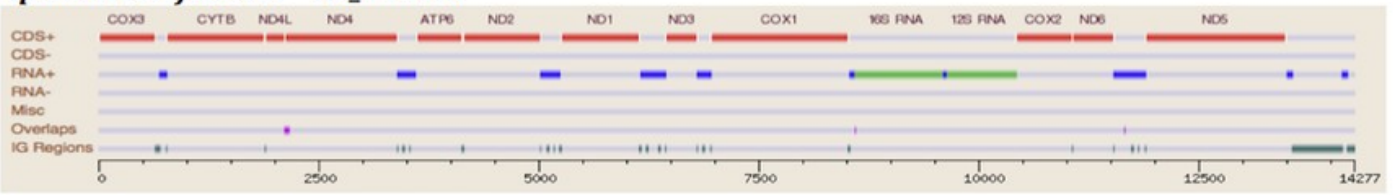

Paragonimus westermani NC_002354

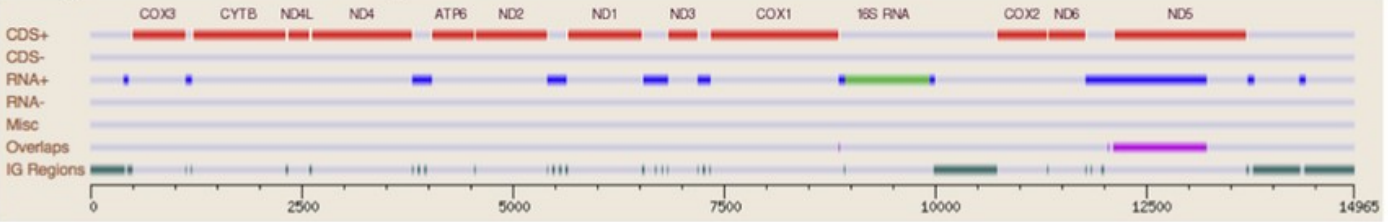

Fasciola gigantica NC_024025

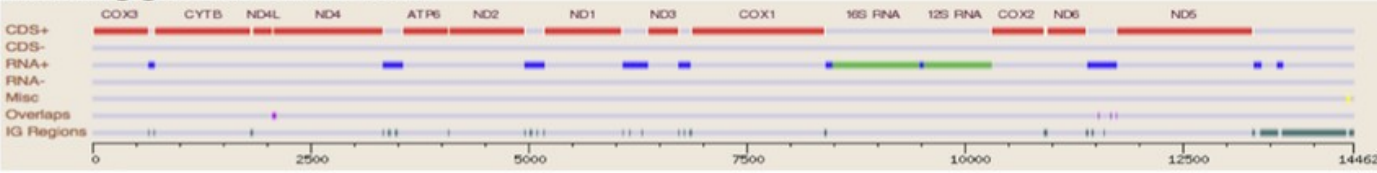

Fasciola hepatica NC_002546

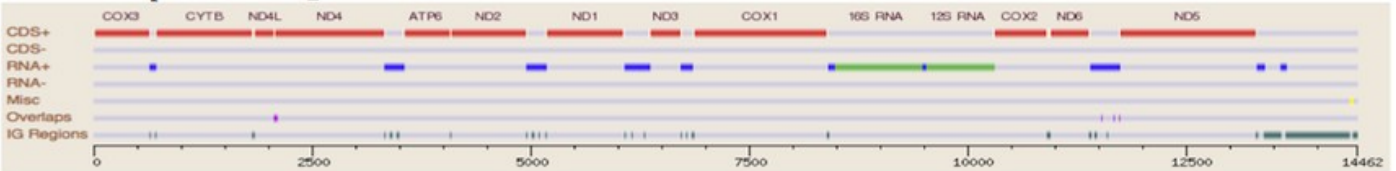

Taenia saginata NC_009938

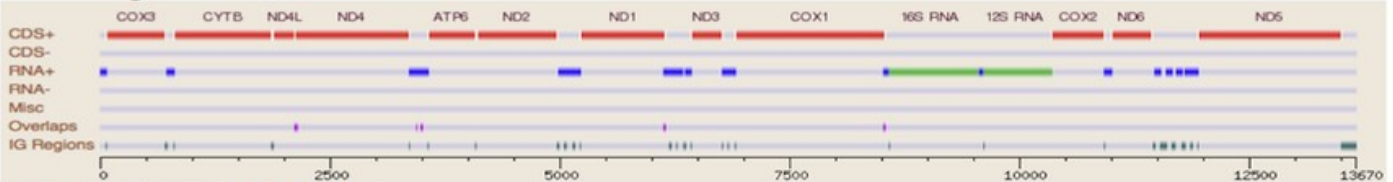

Taenia solium NC_004022

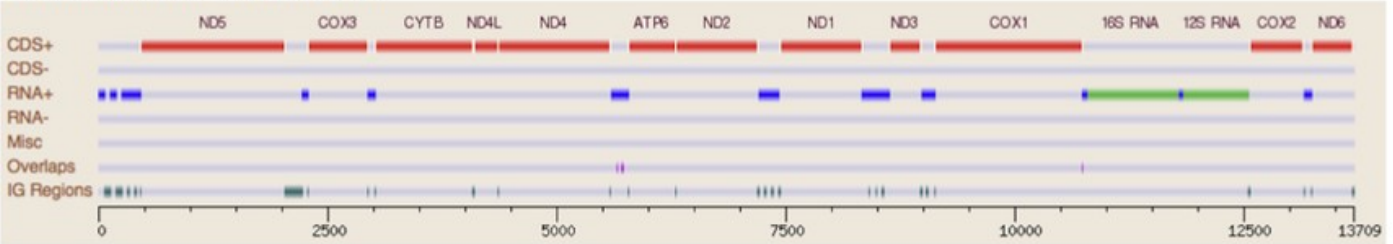

Ascaris lumbricoides JN801161
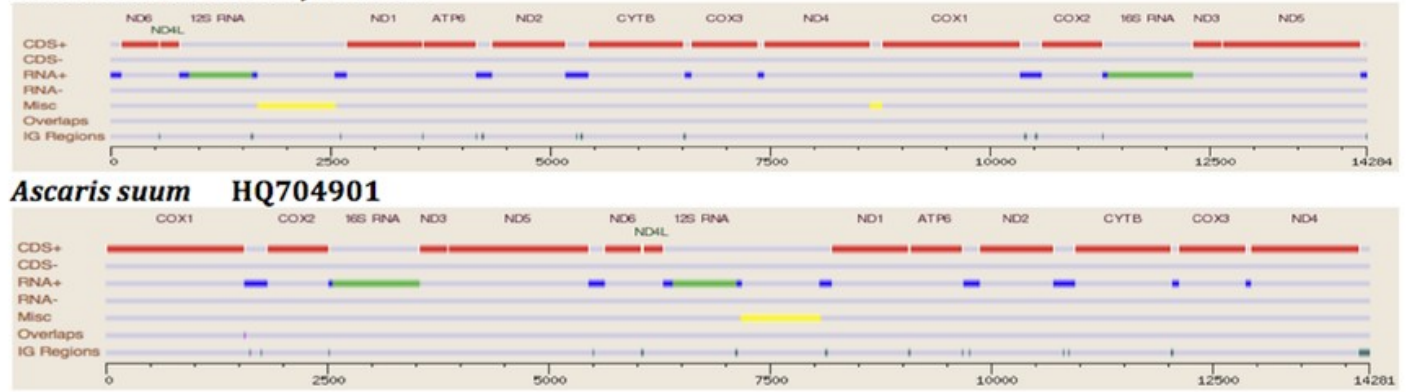


\section{Figure 2}

Circular genome map of Paragonimus westermani mtDNA

The manual and in-silico annotations with appropriate regions for P. westermani mtDNA and annotated GenBank flat file for P. westermani were drawn into a circular graph in GenomeVX depicting the 12 PCGs and 24tRNAs. 


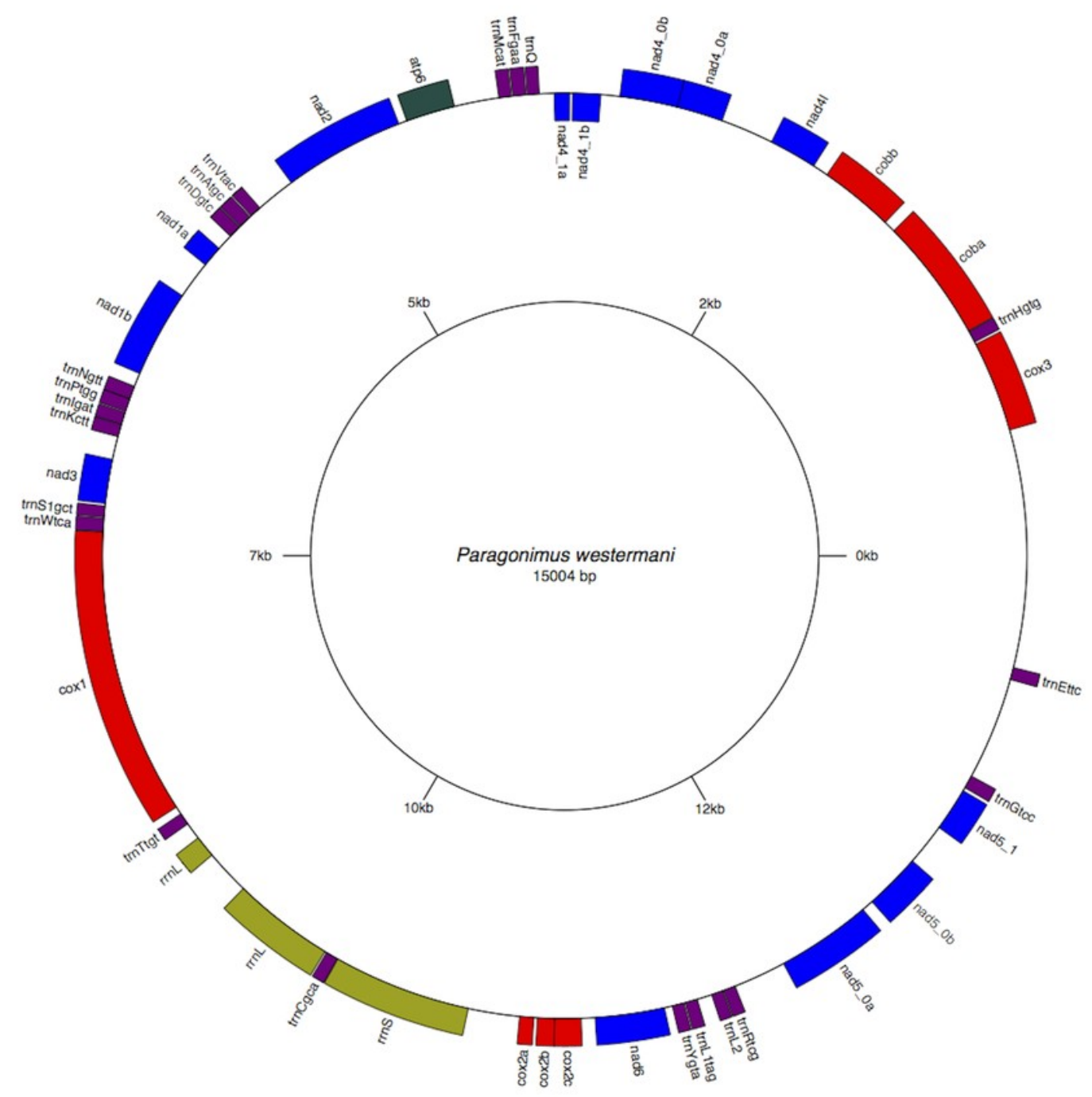




\section{Figure 3}

Inferred Phylogenetic relationship among the representative helminth mtDNA species of the concatenated 12 protein coding genes

Trees were inferred using MrBayes v3.1. A, tree inferred from concatenated nucleotide sequences of 12 protein-coding genes, using the cestode Echinococcus granulosus as the outgroup. Posterior support values are given at nodes. Differences in the gene order in the mitochondrial genomes of parasitic flatworms from the Trematoda and Cestoda and taking Nematoda (Ascaridida) as an outgroup are indictaed on the phylogenetic leaf nodes. See text for more details.

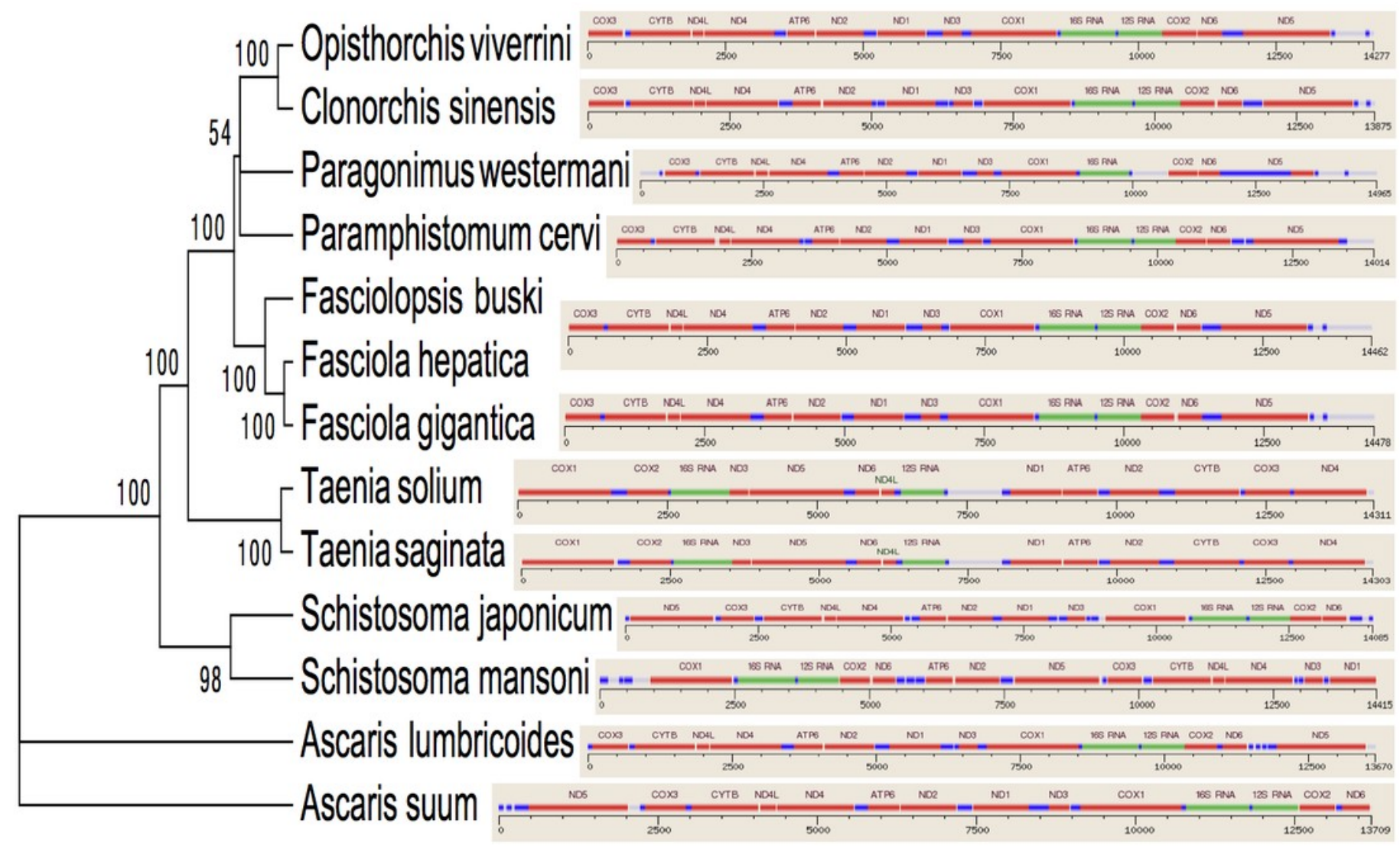




\section{Figure 4}

Summarized 12 protein coding genes and their blast hit protein plots

The protein plot depicts the quality value for each gene and each position if it is above the threshold and the different genes are differentiated with a range of colour codes. The hits used in MITOS correspond to the "mountains" in this protein plot that visualizes the signal from the BLAST searches. The arrows shown on the top of the plot depict gene order annotation and the quality values are shown on a log scale.

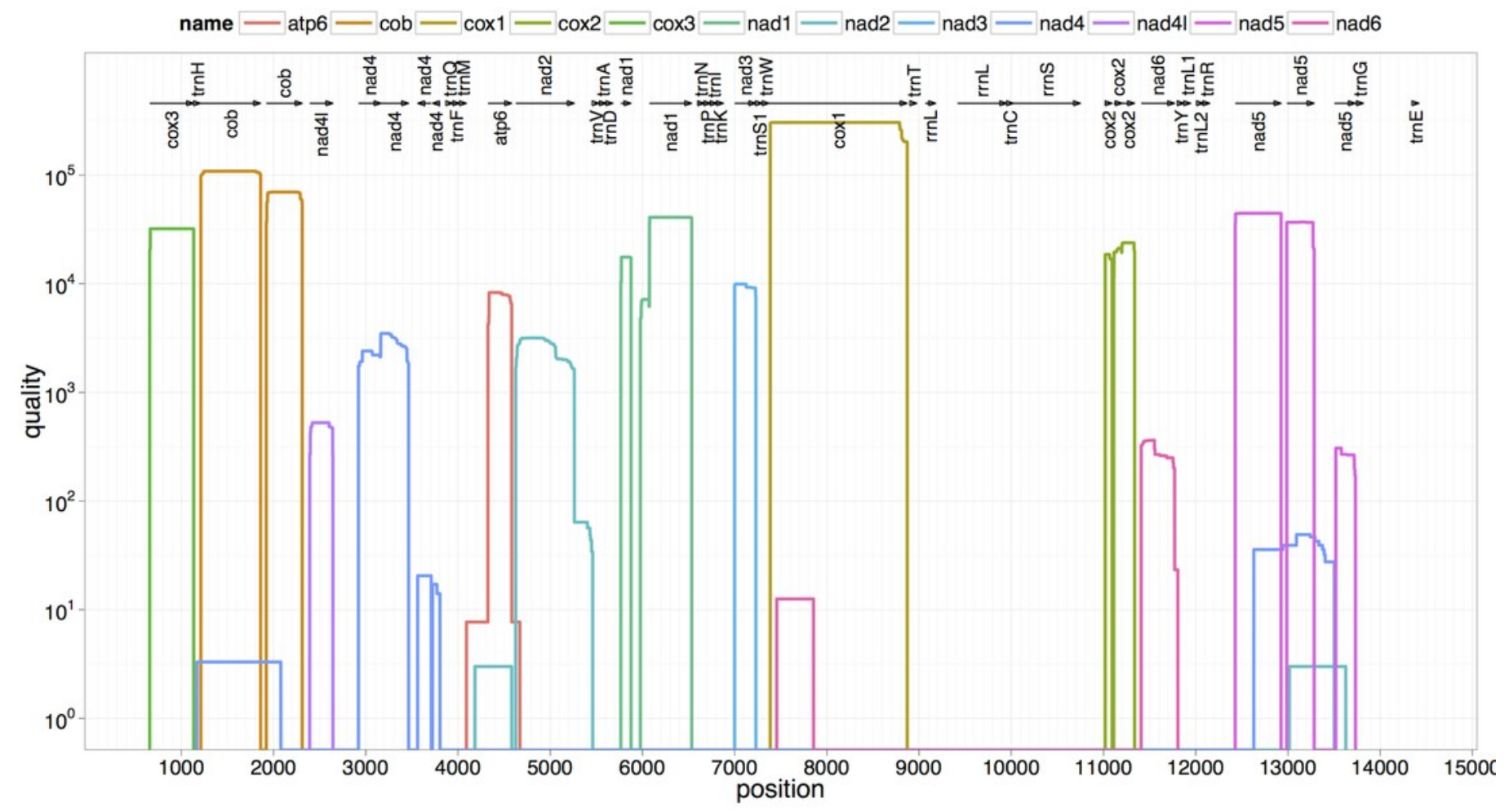




\section{Figure 5}

Dot plot matrix and sequence similarity map depicting the the sequence similarity regions between the assembled and reference mtDNA.

A. Dot plot matrix between the reference and assembled $\mathrm{mt}$ DNA. X-axis represents the assembled sequence, whereas y-axis represents the reference sequence. B. Visual output of the mapped assembled mtDNA against the reference mtDNA using standalone blast and Artemis Comparison Tool (ACT).
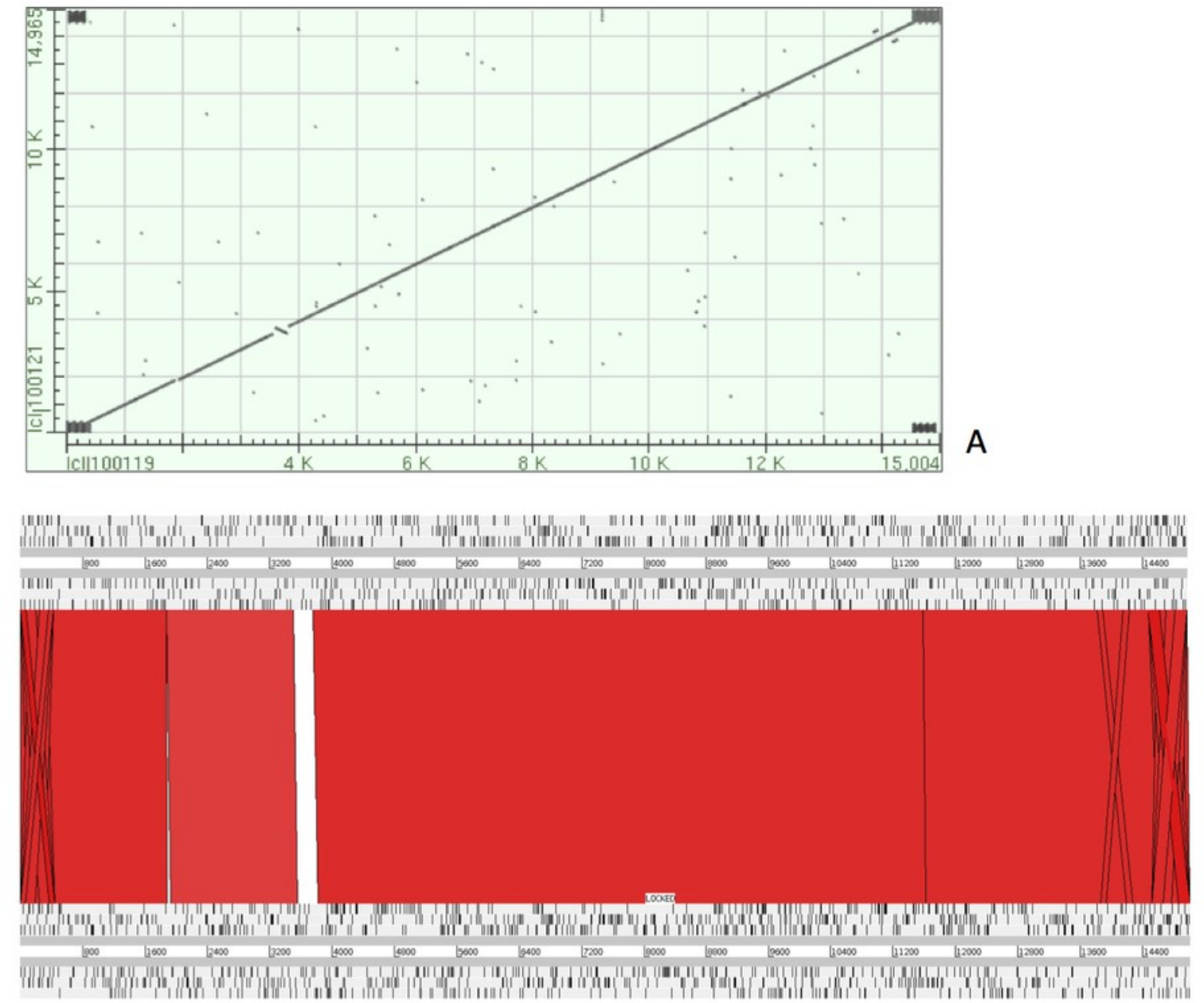


\section{Figure 6}

Comparative histogram of the nucleotide frequences of the Indian and Korean P. westermani isolates.

Blue coloured bars indicate Indian isolate while dark coloured bars indicate the reference Korean isolate deposited in GenBank.

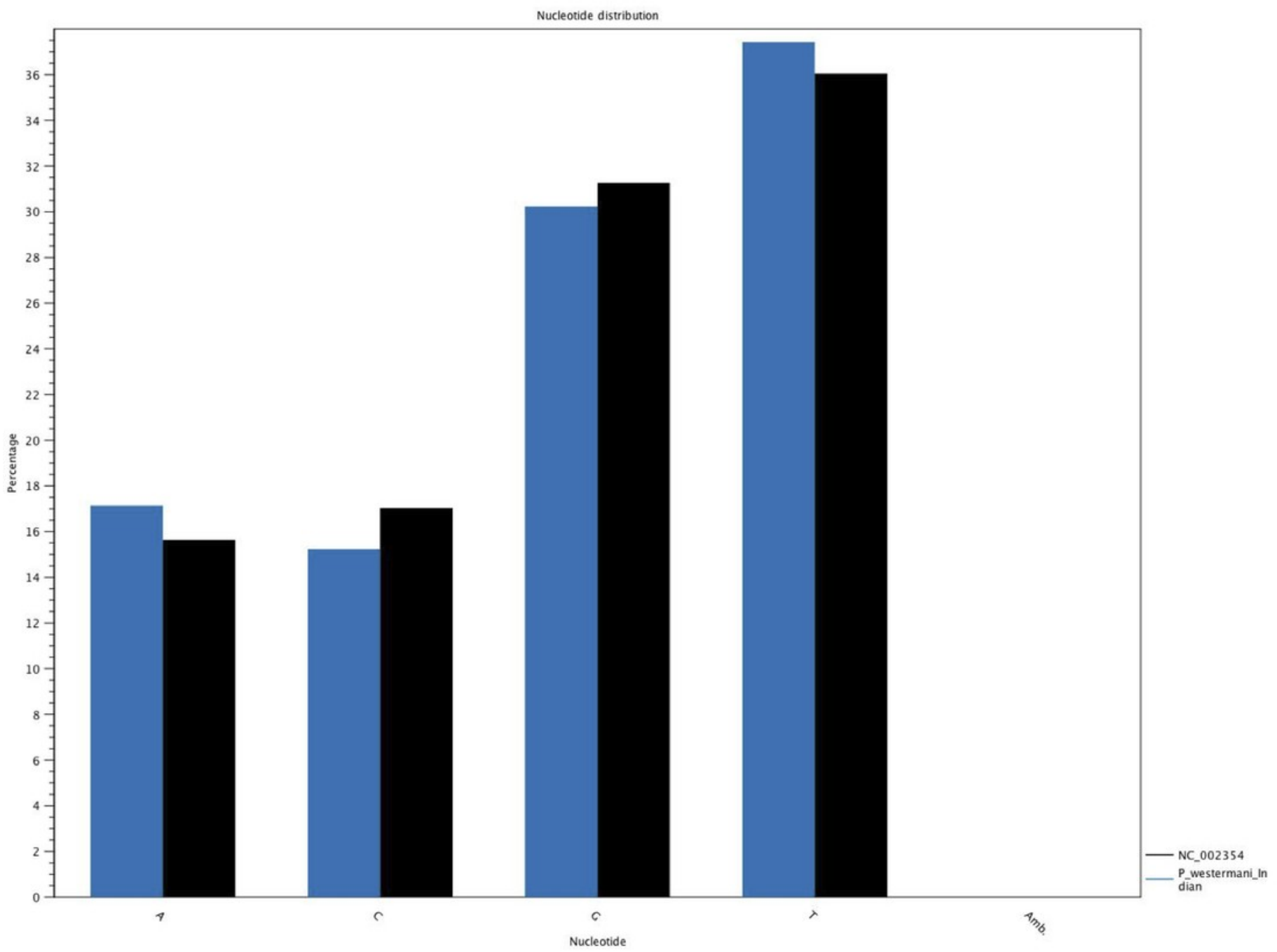




\section{Figure 7}

24 tRNA secondary structures predicted using ARWEN 


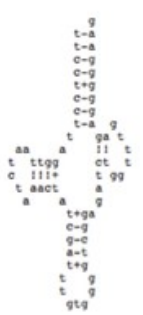

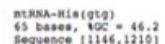

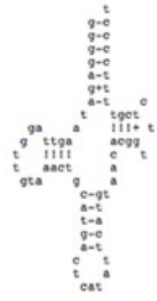

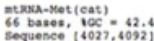

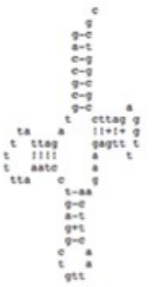

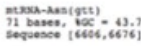

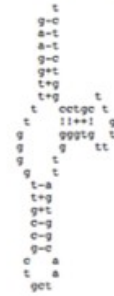

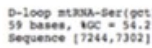

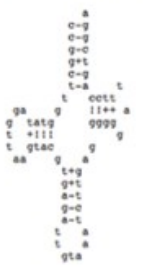

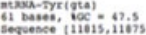

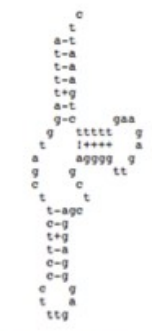

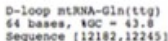

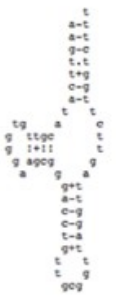

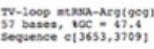

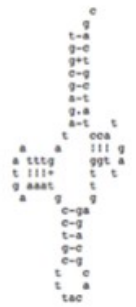

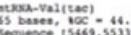

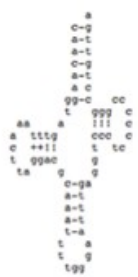

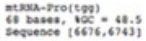

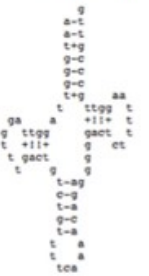

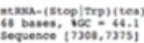

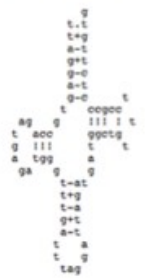

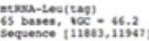

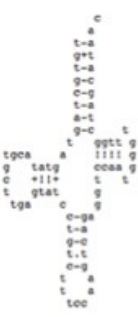

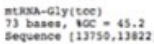

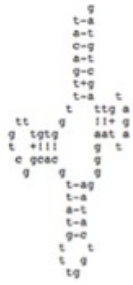

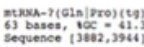

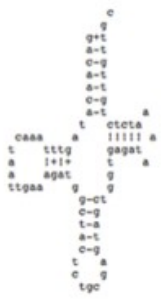

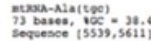

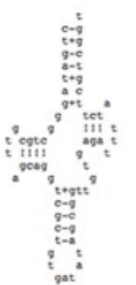

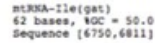

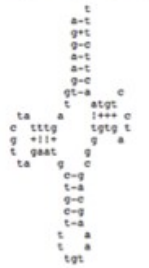

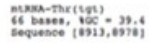

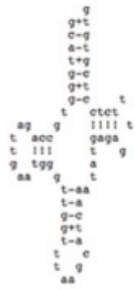

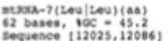

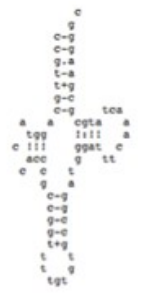

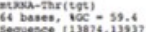

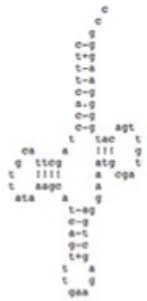

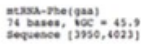

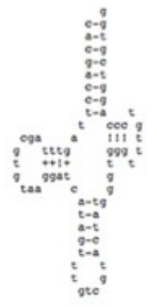

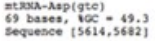
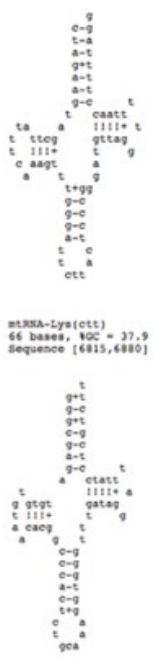

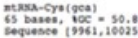

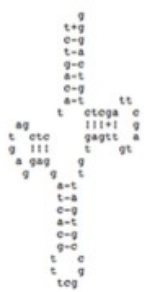

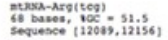

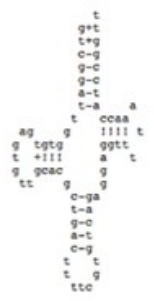

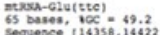




\section{Table 1 (on next page)}

mt DNA nucleotide sequence statistics information of representative helminth parasites 
Table 1. Mitochondrial DNA Nucleotide sequence statistics information of selected digenean trematodes, cestodes and nematodes

\begin{tabular}{|c|c|c|c|c|c|c|c|c|c|c|c|c|c|}
\hline $\begin{array}{c}\text { Sequence } \\
\text { type }\end{array}$ & DNA & DNA & + DNA & DNA & DNA & DNA & DNA & DNA & DNA & DNA & DNA & DNA & DNA \\
\hline Length & $\begin{array}{l}14,118 \text { bp } \\
\text { circular }\end{array}$ & $\begin{array}{l}14,462 \mathrm{bp} \\
\text { circular }\end{array}$ & $\begin{array}{l}\frac{\overline{1}}{\mathrm{~d}} 5,004 \mathrm{bp} \\
\frac{\mathscr{D}}{\supset} \text { circular }\end{array}$ & $\begin{array}{c}14,277 \mathrm{bp} \\
\text { circular }\end{array}$ & $\begin{array}{l}14014 \mathrm{bp} \\
\text { circular }\end{array}$ & $\begin{array}{c}13,875 b \\
p \\
\text { circular }\end{array}$ & $\begin{array}{l}14,478 \text { bp } \\
\text { circular }\end{array}$ & $\begin{array}{l}14,415 \mathrm{bp} \\
\text { circular }\end{array}$ & $\begin{array}{l}14,085 \mathrm{bp} \\
\text { circular }\end{array}$ & $\begin{array}{l}13,670 \mathrm{bp} \\
\text { circular }\end{array}$ & $\begin{array}{c}13,709 \\
\text { bp } \\
\text { circular }\end{array}$ & $\begin{array}{c}14,281 \\
\text { bp circular }\end{array}$ & $\begin{array}{c}14,284 \\
\text { bp } \\
\text { circular }\end{array}$ \\
\hline $\begin{array}{l}\text { Organism } \\
\text { Name }\end{array}$ & $\begin{array}{l}\text { Fasciolops } \\
\text { is buski }\end{array}$ & $\begin{array}{l}\text { Fasciola } \\
\text { hepatica }\end{array}$ & $\begin{array}{l}\sum_{\text {Puragonimus }} \\
\text { Mestermani }\end{array}$ & $\begin{array}{c}\text { Opisthorc } \\
\text { his } \\
\text { felineus }\end{array}$ & $\begin{array}{l}\text { Paramphist } \\
\text { omum cervi }\end{array}$ & $\begin{array}{c}\text { Clonor } \\
\text { chis } \\
\text { sinensi } \\
\quad s\end{array}$ & $\begin{array}{l}\text { Fasciola } \\
\text { gigantica }\end{array}$ & $\begin{array}{c}\text { Schistosoma } \\
\text { mansoni }\end{array}$ & $\begin{array}{l}\text { Schistosoma } \\
\text { japonicum }\end{array}$ & $\begin{array}{c}\text { Taenia } \\
\text { saginata }\end{array}$ & $\begin{array}{l}\text { Taenia } \\
\text { solium }\end{array}$ & $\begin{array}{c}\text { Ascaris } \\
\text { lumbricoides }\end{array}$ & $\begin{array}{c}\text { Ascaris } \\
\text { suum }\end{array}$ \\
\hline Accession & $\begin{array}{c}\text { Submitted } \\
\text { to } \\
\text { GenBank }\end{array}$ & NC_00254 & $\frac{d}{\mathrm{~N} C} \_002354$ & EU921260 & NC_023095 & $\begin{array}{c}\text { FJ3816 } \\
64\end{array}$ & $\mathrm{NC}_{-}^{0} 02402$ & NC_002545 & NC_002544 & $\begin{array}{c}\mathrm{NC}_{9-009} 009 \\
938\end{array}$ & $\begin{array}{c}\mathrm{NC}_{-} 00 \\
4022\end{array}$ & JN801161 & $\begin{array}{c}\mathrm{NC} \_00 \\
1327\end{array}$ \\
\hline $\begin{array}{c}\text { Modificat } \\
\text { ion Date }\end{array}$ & submitted & $\begin{array}{c}\text { 01-FEB- } \\
2010\end{array}$ & Submitted & $\begin{array}{c}\text { 18-AUG- } \\
2010\end{array}$ & $\begin{array}{c}\text { 14-JAN- } \\
2014\end{array}$ & $\begin{array}{c}\text { 01- } \\
\text { JUL- } \\
2010\end{array}$ & $\begin{array}{l}\text { 01-MAY- } \\
2014\end{array}$ & $\begin{array}{l}\text { 14-APR- } \\
2009\end{array}$ & $\begin{array}{l}\text { 01-FEB- } \\
2010\end{array}$ & $\begin{array}{c}\text { 14-APR- } \\
2009\end{array}$ & $\begin{array}{l}01- \\
\text { FEB- } \\
2010\end{array}$ & 01-DEC-2011 & $\begin{array}{l}11- \\
\text { MAR- } \\
2010\end{array}$ \\
\hline $\begin{array}{c}\text { Weight } \\
\text { (single- } \\
\text { stranded) }\end{array}$ & 4396.507 & $\begin{array}{c}4,499.496 \\
\mathrm{kDa}\end{array}$ & , & $\begin{array}{c}4,437.683 \\
\mathrm{kDa}\end{array}$ & $\begin{array}{c}4,363.551 \\
\mathrm{kDa}\end{array}$ & $\begin{array}{l}4,311.8 \\
34 \mathrm{kDa}\end{array}$ & $\begin{array}{c}4,504.913 \\
\mathrm{kDa}\end{array}$ & $\begin{array}{c}4,482.165 \\
\mathrm{kDa}\end{array}$ & $\begin{array}{c}4,371.002 \\
\mathrm{kDa}\end{array}$ & $\begin{array}{c}4,242.42 \\
5 \mathrm{kDa}\end{array}$ & $\begin{array}{l}4,251.9 \\
92 \mathrm{kDa}\end{array}$ & $4,428.619 \mathrm{kDa}$ & $\begin{array}{l}4,429.9 \\
81 \mathrm{kDa}\end{array}$ \\
\hline $\begin{array}{c}\text { Weight } \\
\text { (double- } \\
\text { stranded) }\end{array}$ & 8721.667 & $\begin{array}{c}8,934.244 \\
\mathrm{kDa}\end{array}$ & $9,270.244 \mathrm{kDa}$ & $\begin{array}{c}8,820.283 \\
\mathrm{kDa}\end{array}$ & $\begin{array}{c}8,657.348 \\
\mathrm{kDa}\end{array}$ & $\begin{array}{l}8,571.8 \\
88 \mathrm{kDa}\end{array}$ & $\begin{array}{c}8,944.06 \\
\mathrm{kDa}\end{array}$ & $\begin{array}{c}8,904.302 \\
\mathrm{kDa}\end{array}$ & $\begin{array}{c}8,700.11 \\
\mathrm{kDa}\end{array}$ & $\begin{array}{c}8,443.71 \\
1 \mathrm{kDa}\end{array}$ & $\begin{array}{l}8,467.7 \\
23 \mathrm{kDa}\end{array}$ & 8,443.711 kDa & $\begin{array}{l}8,822.8 \\
99 \mathrm{kDa}\end{array}$ \\
\hline \multicolumn{14}{|c|}{ Annotation table } \\
\hline $\begin{array}{c}\text { Featutre } \\
\text { type }\end{array}$ & Count & Count & Count & Count & Count & Count & Count & Count & Count & Count & & Count & Count \\
\hline CDS & 12 & 12 & 12 & 12 & 12 & 12 & 12 & 12 & 12 & 12 & 12 & 12 & 12 \\
\hline Gene & 12 & 12 & 12 & 12 & 12 & 12 & 12 & 12 & 12 & 12 & 12 & 12 & 12 \\
\hline $\begin{array}{c}\text { Misc. } \\
\text { feature }\end{array}$ & 1 & 1 & - & - & - & - & & 1 & 1 & - & - & 1 & 2 \\
\hline rRNA & 2 & 2 & 2 & 2 & 2 & 2 & 2 & 2 & 2 & 2 & 2 & 2 & 2 \\
\hline tRNA & 22 & 22 & 24 & 22 & 22 & 22 & 22 & 23 & 23 & 22 & 22 & 22 & 22 \\
\hline
\end{tabular}




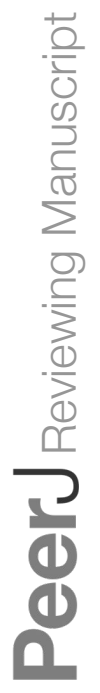

PeerJ reviewing PDF | (v2014:05:2165:2:0:NEW 22 Jun 2014) 


\section{Table 2 (on next page)}

P. westermani mtDNA annotations showing PCGs and tRNA in dot bracket format 
Table 2. P. westermani mtDNA annotations showing PCGs and tRNAs in dot bracket format

\begin{tabular}{|c|c|c|c|c|c|}
\hline Name & Start & Stop & Strand & Length & Structure \\
\hline $\operatorname{cox} 3$ & 658 & 1134 & + & 477 & \\
\hline $\operatorname{trnH}($ gtg $)$ & 1147 & 1209 & + & 63 & $(((((((. . .((((\ldots \ldots)))).) \cdot(((((\ldots \ldots .))))).) \ldots .((.(.))))))))))))$. \\
\hline cob-a & 1213 & 1860 & + & 648 & \\
\hline cob-b & 1922 & 2311 & + & 390 & \\
\hline $\operatorname{nad} 41$ & 2393 & 2644 & + & 252 & \\
\hline nad4_0-a & 2922 & 3167 & + & 246 & \\
\hline nad4_0-b & 3163 & 3465 & + & 303 & \\
\hline nad4_1-b & 3564 & 3710 & - & 147 & \\
\hline nad4_1-a & 3725 & 3805 & - & 81 & \\
\hline $\operatorname{trnQ}(---)$ & 3882 & 3944 & + & 63 & $(((((((. .((((\ldots \ldots .)))).) \cdot(((((\ldots \ldots))))).) \ldots(((\ldots \ldots . .))))))))))$. \\
\hline $\operatorname{trnF}$ (gaa) & 3951 & 4020 & + & 70 & $((((.((. .((((\ldots \ldots \ldots))))) \cdot(((((\ldots \ldots .))))).) \ldots((((\ldots \ldots \ldots)))))) \cdot)))))$. \\
\hline $\operatorname{trnM}$ (cat) & 4027 & 4092 & + & 66 & $(((((((. .((((\ldots \ldots \ldots)))) \cdot(((((\ldots \ldots \ldots))))) \ldots . .((((\ldots))))))))))))$ \\
\hline atp6 & 4326 & 4583 & + & 258 & \\
\hline $\operatorname{nad} 2$ & 4627 & 5262 & + & 636 & \\
\hline $\operatorname{trnV}(\operatorname{tac})$ & 5470 & 5531 & + & 62 & $(((((.(. .((((\ldots .)))).) \cdot(((((\ldots \ldots .))))).) \ldots((((\ldots))))))))))$. \\
\hline $\operatorname{trn} A(\operatorname{tgc})$ & 5539 & 5610 & + & 72 & $(((((((. .((((\ldots \ldots \ldots \ldots \ldots))))) \cdot(((((\ldots \ldots \ldots)))))) \ldots .(((((\ldots)))))))))))))$. \\
\hline $\operatorname{trnD}(\mathrm{gtc})$ & 5615 & 5681 & + & 67 & $(((((((. .((((\ldots \ldots \ldots . .))).) \cdot(((((\ldots \ldots .))))).) \ldots((((\ldots .)))))))))))$. \\
\hline nad1-a & 5767 & 5877 & + & 111 & \\
\hline nad1-b & 6077 & 6535 & + & 459 & \\
\hline $\operatorname{trnN}(\mathrm{gtt})$ & 6606 & 6675 & + & 70 & $(((((((. .((((\ldots \ldots \ldots)))) \cdot(((((\ldots \ldots .))))).) \ldots . .(((((\ldots . .))))))))))))$.$) .$ \\
\hline $\operatorname{trnP}(\operatorname{tgg})$ & 6676 & 6743 & + & 68 & $((((.(((. .((((\ldots \ldots)))).) \cdot(((((\ldots \ldots .))))).) \ldots .(((\ldots \ldots .)))))))))))$. \\
\hline $\operatorname{trnI}($ gat $)$ & 6749 & 6812 & + & 64 & $((((((.(. .((((\ldots)))).) \cdot(((((\ldots \ldots . .))))).) \ldots .(((((.)))))))))))))$. \\
\hline $\operatorname{trnK}(\mathrm{ctt})$ & 6815 & 6880 & + & 66 & $(((((((. .((((\ldots \ldots)))).) \cdot(((((\ldots \ldots .))))).) \ldots(((((\ldots))))))))))))))$. \\
\hline $\operatorname{nad} 3$ & 7001 & 7231 & + & 231 & \\
\hline $\operatorname{trnS1}(\mathrm{gct})$ & 7244 & 7302 & + & 59 & $(((((((\ldots \ldots . .(((((\ldots \ldots .))))).) \ldots . .(((((\ldots \ldots)))))))))))))$. \\
\hline $\operatorname{trnW}(\mathrm{tca})$ & 7308 & 7375 & + & 68 & $(((((((. .((((\ldots \ldots))))) \cdot(((((\ldots \ldots .))))).) \ldots . .((((\ldots \ldots .))))))))))))$. \\
\hline $\operatorname{cox} 1$ & 7379 & 8872 & + & 1494 & \\
\hline $\operatorname{trnT}(\operatorname{tgt})$ & 8914 & 8977 & + & 64 & $((((((\ldots)((((\ldots \ldots))).) \cdot(((((\ldots \ldots))))).) \ldots .(((\ldots .))).) \cdot))))))$. \\
\hline $\mathrm{rrnL}$ & 9067 & 9181 & + & 115 & 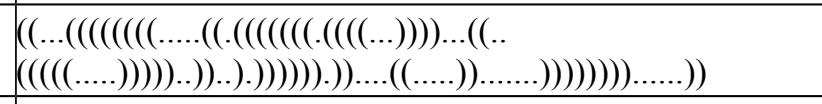 \\
\hline $\mathrm{rrnL}$ & 9417 & 9951 & + & 535 & 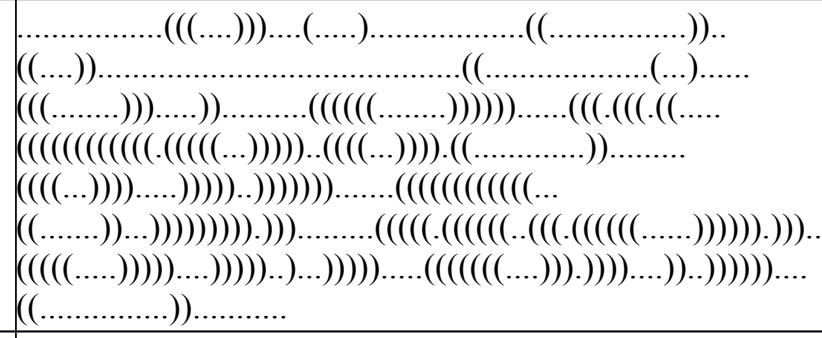 \\
\hline $\operatorname{trnC}($ gca $)$ & 9961 & 10025 & + & 65 & $(((((((. .((((\ldots))))) \ldots(((((\ldots \ldots .)))).) \ldots . .(((((\ldots)))))))))))))$ \\
\hline $\mathrm{rrnS}$ & 10028 & 10751 & + & 724 & 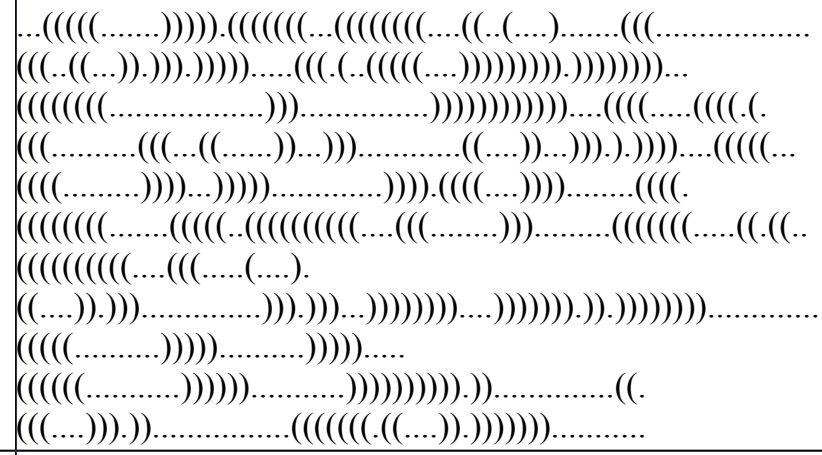 \\
\hline $\operatorname{cox} 2-\mathrm{a}$ & 11020 & 11094 & + & 75 & \\
\hline \multicolumn{6}{|c|}{$(1+12614: 05: 2463: 2040: 0$} \\
\hline $\operatorname{cox} 2-c$ & 11201 & 11338 & + & 138 & \\
\hline
\end{tabular}




\begin{tabular}{|c|c|c|c|c|c|}
\hline nad6 & 11410 & 11772 & + & 363 & \\
\hline $\operatorname{trn} Y($ gta $)$ & 11814 & 11876 & + & 63 & $\cdot((((((. .((((\ldots \ldots .)))).) \cdot(((((\ldots \ldots .))))).) \ldots .(((())))))))))).) .$. \\
\hline $\operatorname{trnL1(tag)}$ & 11883 & 11947 & + & 65 & $.((((((. .(((\ldots \ldots .)))) ..(((((\ldots \ldots))))).) \ldots . .(((.(\ldots))))))))))))$. \\
\hline $\operatorname{trnL2(---)}$ & 12025 & 12086 & + & 62 & $(((((((. .(((\ldots \ldots .))).) \cdot((((\ldots \ldots . .))).) \ldots . .((((()))))))))))))$. \\
\hline $\operatorname{trnR}(\operatorname{tcg})$ & 12091 & 12154 & + & 64 & $(((((((((\ldots \ldots)))).) \cdot(((((\ldots \ldots \ldots)))))) \ldots .(((((\ldots \ldots .))))))))))$.$) .$ \\
\hline nad5_0-a & 12430 & 12927 & + & 498 & \\
\hline nad5_0-b & 12989 & 13285 & + & 297 & \\
\hline nad5_1 & 13506 & 13733 & + & 228 & \\
\hline $\operatorname{trnG(tcc)}$ & 13751 & 13820 & + & 70 & $(((((((. .((((\ldots \ldots \ldots .)))).) \cdot(((.(\ldots \ldots .))))).) \ldots(((((\ldots .)))))))))))))$. \\
\hline $\operatorname{trnE}(\mathrm{ttc})$ & 14358 & 14422 & + & 65 & $(((((((. .((((\ldots \ldots .)))).) \cdot(((((\ldots \ldots .))))).) \ldots((((\ldots))))))))))))$. \\
\hline
\end{tabular}




\section{Table 3 (on next page)}

Codon usage for Paragonimus westermani mt DNA 
Table 3. Codon usage for Paragonimus westermani mt DNA

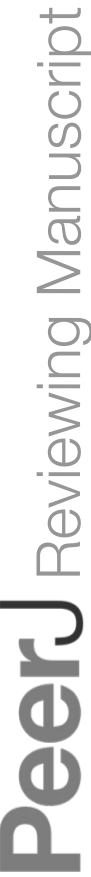

\begin{tabular}{|c|c|c|c|c|}
\hline AmAcid & Codon & Number & $/ 1000$ & Fraction \\
\hline Ala & GCG & 57.00 & 11.40 & 0.27 \\
\hline Ala & $\mathrm{GCA}$ & 38.00 & 7.60 & 0.18 \\
\hline Ala & $\mathrm{GCT}$ & 75.00 & 15.00 & 0.36 \\
\hline Ala & $\mathrm{GCC}$ & 39.00 & 7.80 & 0.19 \\
\hline Cys & TGT & 208.00 & 41.59 & 0.76 \\
\hline Cys & TGC & 67.00 & 13.40 & 0.24 \\
\hline Asp & GAT & 91.00 & 18.20 & 0.72 \\
\hline Asp & GAC & 36.00 & 7.20 & 0.28 \\
\hline $\mathrm{Glu}$ & GAG & 111.00 & 22.20 & 0.69 \\
\hline Glu & GAA & 51.00 & 10.20 & 0.31 \\
\hline Phe & $\mathrm{TTT}$ & 310.00 & 61.99 & 0.74 \\
\hline Phe & TTC & 109.00 & 21.80 & 0.26 \\
\hline Gly & GGG & 168.00 & 33.59 & 0.34 \\
\hline Gly & GGA & 89.00 & 17.80 & 0.18 \\
\hline Gly & GGT & 166.00 & 33.19 & 0.34 \\
\hline Gly & GGC & 66.00 & 13.20 & 0.13 \\
\hline His & $\mathrm{CAT}$ & 44.00 & 8.80 & 0.61 \\
\hline His & CAC & 28.00 & 5.60 & 0.39 \\
\hline Ile & $\mathrm{ATT}$ & 97.00 & 19.40 & 0.71 \\
\hline Ile & ATC & 40.00 & 8.00 & 0.29 \\
\hline Lys & AAG & 66.00 & 13.20 & 1.00 \\
\hline Leu & TTG & 226.00 & 45.19 & 0.34 \\
\hline Leu & TTA & 110.00 & 22.00 & 0.17 \\
\hline Leu & $\mathrm{CTG}$ & 92.00 & 18.40 & 0.14 \\
\hline Leu & $\mathrm{CTA}$ & 35.00 & 7.00 & 0.05 \\
\hline Leu & $\mathrm{CTT}$ & 147.00 & 29.39 & 0.22 \\
\hline Leu & $\mathrm{CTC}$ & 56.00 & 11.20 & 0.08 \\
\hline Met & ATG & 89.00 & 17.80 & 0.80 \\
\hline Met & ATA & 22.00 & 4.40 & 0.20 \\
\hline Asn & AAA & 55.00 & 11.00 & 0.45 \\
\hline Asn & $\mathrm{AAT}$ & 44.00 & 8.80 & 0.36 \\
\hline Asn & AAC & 24.00 & 4.80 & 0.20 \\
\hline Pro & $\mathrm{CCG}$ & 34.00 & 6.80 & 0.26 \\
\hline Pro & $\mathrm{CCA}$ & 20.00 & 4.00 & 0.15 \\
\hline Pro & $\mathrm{CCT}$ & 57.00 & 11.40 & 0.43 \\
\hline Pro & $\mathrm{CCC}$ & 22.00 & 4.40 & 0.17 \\
\hline Gln & CAG & 42.00 & 8.40 & 0.64 \\
\hline Gln & CAA & 24.00 & 4.80 & 0.36 \\
\hline Arg & CGG & 51.00 & 10.20 & 0.35 \\
\hline Arg & CGA & 26.00 & 5.20 & 0.18 \\
\hline Arg & CGT & 51.00 & 10.20 & 0.35 \\
\hline Arg & CGC & 19.00 & 3.80 & 0.13 \\
\hline Ser & AGG & 125.00 & 25.00 & 0.21 \\
\hline Ser & AGA & 57.00 & 11.40 & 0.09 \\
\hline Ser & AGT & 76.00 & 15.20 & 0.13 \\
\hline Ser & AGC & 36.00 & 7.20 & 0.06 \\
\hline Ser & TCG & 56.00 & 11.20 & 0.09 \\
\hline Ser & $\mathrm{TCA}$ & 52.00 & 10.40 & 0.09 \\
\hline Ser & $\mathrm{TCT}$ & 134.00 & 26.79 & 0.22 \\
\hline Ser & TCC & 68.00 & 13.60 & 0.11 \\
\hline Thr & ACG & 37.00 & 7.40 & 0.29 \\
\hline Thr & $\mathrm{ACA}$ & 20.00 & 4.00 & 0.16 \\
\hline Thr & $\mathrm{ACT}$ & 43.00 & 8.60 & 0.34 \\
\hline Thr & $\mathrm{ACC}$ & 27.00 & 5.40 & 0.21 \\
\hline Val & GTG & 156.00 & 31.19 & 0.29 \\
\hline Val & GTA & 58.00 & 11.60 & 0.11 \\
\hline Val & GTT & 256.00 & 51.19 & 0.48 \\
\hline Val & GTC & 65.00 & 13.00 & 0.12 \\
\hline $\operatorname{Trp}$ & TGG & 159.00 & 31.79 & 0.58 \\
\hline $\operatorname{Trp}$ & TGA & 113.00 & 22.60 & 0.42 \\
\hline Tyr & TAT & 74.00 & 14.80 & 0.57 \\
\hline Tyr & TAC & 55.00 & 11.00 & 0.43 \\
\hline
\end{tabular}


66.00

13.20

0.50

End

TAA

66.00

13.20

0.50 


\section{Table 4 (on next page)}

Comparative nucleotide sequence statistics of mtDNA between P. westermani Indian and Korean isolates 
Table 4. Comparative nucleotide sequence statistics of mtDNA between $P$. westermani Indian and Korean isolates

\begin{tabular}{|c|c|c|}
\hline \multicolumn{3}{|l|}{ Sequence information } \\
\hline Information & $\begin{array}{l}\text { P. westermani } \\
\text { Indian }\end{array}$ & $\begin{array}{l}\text { P. westermani Korean, } \\
\text { (NC_002354) }\end{array}$ \\
\hline Sequence type & DNA & DNA \\
\hline Length & 15004 & 14965 \\
\hline Weight (single-stranded) & 4666.455 & 4652.101 \\
\hline Weight (double-stranded) & 9270.244 & 9246.535 \\
\hline \multicolumn{3}{|c|}{ Melting temperatures - degrees Celsius } \\
\hline \multicolumn{3}{|c|}{\begin{tabular}{|l|l} 
[salt] & \\
\end{tabular}} \\
\hline 0.1 & 83.53 & 84.71 \\
\hline 0.2 & 88.53 & 89.7 \\
\hline 0.3 & 91.45 & 92.63 \\
\hline 0.4 & 93.53 & 94.7 \\
\hline 0.5 & 95.14 & 96.31 \\
\hline \multicolumn{3}{|l|}{ Counts of annotations } \\
\hline \multicolumn{3}{|l|}{ Feature type } \\
\hline CDS & 12 & 12 \\
\hline Gene & 12 & 12 \\
\hline Source & 1 & 1 \\
\hline rRNA & 1 & 1 \\
\hline tRNA & 24 & 23 \\
\hline \multicolumn{3}{|c|}{ Counts of atoms (As single-stranded) } \\
\hline \multicolumn{3}{|c|}{ Ambiguous residues are omitted in atom counts. } \\
\hline \multicolumn{3}{|c|}{\begin{tabular}{|l|l|} 
Atoms & \\
\end{tabular}} \\
\hline hydrogen $(\mathrm{H})$ & 185664 & 184951 \\
\hline carbon (C) & 147756 & 147080 \\
\hline nitrogen $(\mathrm{N})$ & 53610 & 53530 \\
\hline oxygen $(\mathrm{O})$ & 93068 & 92834 \\
\hline phosphorus $(\mathrm{P})$ & 15004 & 14963 \\
\hline \multicolumn{3}{|c|}{ Counts of atoms (As double-stranded) } \\
\hline \multicolumn{3}{|c|}{ Ambiguous residues are omitted in atom counts. } \\
\hline \multicolumn{3}{|c|}{\begin{tabular}{|l|l|l} 
Atoms & &
\end{tabular}} \\
\hline hydrogen $(\mathrm{H})$ & 368285 & 366846 \\
\hline carbon (C) & 293261 & 292031 \\
\hline nitrogen $(\mathrm{N})$ & 111847 & 111970 \\
\hline oxygen $(\mathrm{O})$ & 180050 & 179556 \\
\hline phosphorus $(\mathrm{P})$ & 30008 & 29926 \\
\hline \multicolumn{3}{|l|}{ Frequencies of atoms } \\
\hline \multicolumn{3}{|c|}{ As single-stranded } \\
\hline \multicolumn{3}{|c|}{ Ambiguous residues are omitted in atom counts. } \\
\hline Atoms & & \\
\hline
\end{tabular}




\begin{tabular}{|c|c|c|}
\hline hydrogen $(\mathrm{H})$ & 0.375 & 0.375 \\
\hline carbon $(\mathrm{C})$ & 0.298 & 0.298 \\
\hline nitrogen $(\mathrm{N})$ & 0.108 & 0.109 \\
\hline oxygen $(\mathrm{O})$ & 0.188 & 0.188 \\
\hline phosphorus (P) & 0.03 & 0.03 \\
\hline \multicolumn{3}{|c|}{ As double-stranded } \\
\hline \multicolumn{3}{|c|}{ Ambiguous residues are omitted in atom counts. } \\
\hline \multicolumn{3}{|l|}{ Atoms } \\
\hline hydrogen $(\mathrm{H})$ & 0.374 & 0.374 \\
\hline carbon $(\mathrm{C})$ & 0.298 & 0.298 \\
\hline nitrogen $(\mathrm{N})$ & 0.114 & 0.114 \\
\hline oxygen $(\mathrm{O})$ & 0.183 & 0.183 \\
\hline phosphorus $(\mathrm{P})$ & 0.031 & 0.031 \\
\hline \multicolumn{3}{|c|}{ Counts of nucleotides } \\
\hline \multicolumn{3}{|l|}{ Nucleotide } \\
\hline Adenine $(A)$ & 2571 & 2339 \\
\hline Cytosine (C) & 2284 & 2550 \\
\hline Guanine (G) & 4535 & 4679 \\
\hline Thymine $(T)$ & 5614 & 5395 \\
\hline Any nucleotide $(\mathrm{N})$ & 0 & 2 \\
\hline$C+G$ & 6819 & 7229 \\
\hline$A+T$ & 8185 & 7734 \\
\hline \multicolumn{3}{|c|}{ Frequencies of nucleotides } \\
\hline \multicolumn{3}{|l|}{ Nucleotide } \\
\hline Adenine $(\mathrm{A})$ & 0.171 & 0.156 \\
\hline Cytosine (C) & 0.152 & 0.17 \\
\hline Guanine (G) & 0.302 & 0.313 \\
\hline Thymine $(\mathrm{T})$ & 0.374 & 0.361 \\
\hline Any nucleotide $(\mathrm{N})$ & 0 & 0 \\
\hline$C+G$ & 0.454 & 0.483 \\
\hline$A+T$ & 0.546 & 0.517 \\
\hline
\end{tabular}




\section{Table 5 (on next page)}

Summary of illumina and lon-Torrent quality control reads 


\section{Table 5. Ion Torrent and Illumina reads}

\begin{tabular}{|c|c|c|}
\hline \multicolumn{3}{|l|}{ Ion torrent reads } \\
\hline S.No & 1 & 2 \\
\hline Fastq file name & processed reads.fastq & mapped mito.fastq \\
\hline Fastq file size & $239.71 \mathrm{MB}$ & $71.55 \mathrm{MB}$ \\
\hline Time taken for Analysis & 8.75 Seconds & 2.76 Seconds \\
\hline Maximum Read Length & 260 & 260 \\
\hline Minimum Read Length & 35 & 35 \\
\hline Mean Read Length & 121 & 117 \\
\hline Total Number of Reads & 890504 & 292832 \\
\hline Total Number of HQ Reads $1^{*}$ & 890442 & 292822 \\
\hline Percentage of HQ Reads & $99.993 \%$ & $99.997 \%$ \\
\hline Total Number of Bases & 107866584 bases & 34145801 bases \\
\hline Total Number of Bases in $\mathrm{Mb}$ & $107.8666 \mathrm{Mb}$ & $34.1458 \mathrm{Mb}$ \\
\hline Total Number of HQ Bases $2 *$ & 105216008 bases & 33218357 bases \\
\hline Total Number of HQ Bases in $\mathrm{Mb}$ & $105.2160 \mathrm{Mb}$ & $33.2184 \mathrm{Mb}$ \\
\hline Percentage of HQ Bases & $97.543 \%$ & $97.284 \%$ \\
\hline Total Number of Non-ATGC Characters & 0 bases & 0 bases \\
\hline $\begin{array}{l}\text { Total Number of Non-ATGC Characters in } \\
\mathrm{Mb}\end{array}$ & $0.000000 \mathrm{Mb}$ & $0.000000 \mathrm{Mb}$ \\
\hline Percentage of Non-ATGC Characters & $0.000 \%$ & $0.000 \%$ \\
\hline $\begin{array}{l}\text { Number of Reads with Non-ATGC } \\
\text { Characters }\end{array}$ & 0 & 0 \\
\hline $\begin{array}{l}\text { Percentage of Reads with Non-ATGC } \\
\text { Characters }\end{array}$ & $0.000 \%$ & $0.000 \%$ \\
\hline \multicolumn{3}{|l|}{ Illumina reads } \\
\hline \multicolumn{2}{|l|}{ S.No } & 1 \\
\hline \multicolumn{2}{|l|}{ Fastq file name } & SE ill.fastq \\
\hline \multicolumn{2}{|l|}{ Fastq file size } & $14.56 \mathrm{MB}$ \\
\hline \multicolumn{2}{|l|}{ Time taken for Analysis } & 0.48 Seconds \\
\hline \multicolumn{2}{|l|}{ Maximum Read Length } & 100 \\
\hline \multicolumn{2}{|l|}{ Minimum Read Length } & 50 \\
\hline \multicolumn{2}{|l|}{ Mean Read Length } & 96 \\
\hline \multicolumn{2}{|l|}{ Total Number of Reads } & 62874 \\
\hline \multicolumn{2}{|l|}{ Total Number of HQ Reads $1 *$} & 62874 \\
\hline \multicolumn{2}{|l|}{ Percentage of HQ Reads } & $100.000 \%$ \\
\hline \multicolumn{2}{|l|}{ Total Number of Bases } & 6053872 bases \\
\hline \multicolumn{2}{|l|}{ Total Number of Bases in $\mathrm{Mb}$} & $6.0539 \mathrm{Mb}$ \\
\hline \multicolumn{2}{|l|}{ Total Number of HQ Bases $2 *$} & 5982733 bases \\
\hline \multicolumn{2}{|l|}{ Total Number of HQ Bases in Mb } & $5.9827 \mathrm{Mb}$ \\
\hline \multicolumn{2}{|l|}{ Percentage of HQ Bases } & $98.825 \%$ \\
\hline \multicolumn{2}{|l|}{ Total Number of Non-ATGC Characters } & 410 bases \\
\hline \multicolumn{2}{|l|}{ Total Number of Non-ATGC Characters in $\mathrm{Mb}$} & $0.000410 \mathrm{Mb}$ \\
\hline \multicolumn{2}{|l|}{ Percentage of Non-ATGC Characters } & $0.007 \%$ \\
\hline \multicolumn{2}{|c|}{ Number of Reads with Non-ATGC Characters } & 240 \\
\hline \multicolumn{2}{|c|}{ Percentage of Reads with Non-ATGC Characters } & $0.382 \%$ \\
\hline
\end{tabular}

